\title{
Experiential Learning Through Classroom Experiments
}

David Bowes, Southeastern Louisiana University Jay Johnson, Southeastern Louisiana University

\begin{abstract}
This paper describes classroom experiments in cooperative behavior as examples of experiential learning in economics classes. Several games are briefly discussed and a new game in cartel behavior is presented. In this game, Students make production decisions as a cartel and earn revenues based on their own output decision and the output decision of the rest of the cartel. Cooperative behavior generates maximum profit for the group, but individuals have incentive to break from the group. The demonstration can be used to illustrate profit maximizing decisions for a cooperative oligopoly and for individual firms, to introduce strategic behavior and game theory, and to demonstrate the instability of cartels. The paper includes review of other papers and experiments in cooperative behavior, a description of and instructions for the cartel experiment, analysis of results of the experiment, and suggested questions and topics for classroom discussion.
\end{abstract}

Keywords: Inductive Teaching, Experimental Economics, Cartels

\section{INTRODUCTION}

¿

n-class experiments and demonstrations can be effective teaching tools in economics because they allow students to understand economic behavior through direct experience. For example, market games such as the double oral auction allow students to gain an appreciation for how a market achieves equilibrium because they themselves make trades and settle on the equilibrium price, even without necessarily knowing how the market model works (DeYoung, 1993). Economics experiments like this are an example of what Yakhou and Dorweiler (2007) describe as a "student discovery-based pedagogy" or "active learning". The students become directly involved in the learning process. Even though a classroom experiment is part of a controlled environment, Yakhou and Dorweiler point out that direct experience is valuable "whether the activities are real or are part of a created environment." An added advantage of some classroom experiments is that they can give students an appreciation of economic behavior that they are not as likely to experience in their own life. One such behavior is that of a cooperative oligopoly, or cartel.

In this paper we describe classroom experiments in cooperative behavior as examples of experiential learning in economics classes and also offer an original classroom experiment in which students have the opportunity to behave as a cartel. The game demonstrates the behavior of a cartel as maximizing profits by limiting output and behaving as a monopoly. It also demonstrates the idea that cartels are unlikely to last because of incentives to each member to cheat on the cartel agreement, an idea presented by George Stigler in his important 1964 paper. Actions and outcomes in this experiment also demonstrate concepts such as profit maximizing behavior, marginal revenue, and game theory. The game can be played in about 40 minutes, allowing time for both the game and some discussion within a one-hour class period.

\section{PRIOR LITERATURE}

There are several papers that have introduced games that involve oligopoly or cooperative behavior and that show the various ways that cooperative (or uncooperative) behavior can be demonstrated in the classroom. All of these games have merit and focus on cooperative decisions in different ways. Seiver (1995) offers a simple game 
in which the participants first are shown the classic prisoner's dilemma payoff matrix to introduce the idea of game theory in matrix form. Then teams are presented a $3 \times 3$ pricing strategy payoff matrix for two firms. The teams, representing each firm, must choose a price on their own. Of course, the matrix is set up as a prisoner's dilemma, so that the Nash equilibrium decision is not profit maximizing for either firm. Participants are then asked to describe how the ability to cooperate would change the teams' decisions. Seiver's game is limited to only two firms, and no suggestion is made in the description of this game that it could be used to illustrate the incentives facing a cartel or the dangers of collusive agreements, but it is a very good way to introduce the notion of cooperative behavior and the classic prisoners' dilemma.

Capra and Holt (1999) describe a cooperation game in which, like our cartel game, participants use playing cards to reveal their decision. However, in the Capra and Holt game only one card is used, red or black, to indicate a level of work effort, low or high. High effort receives a payoff of $\$ 4$ only when all players choose high effort; otherwise it pays $\$ 0$. Low effort always offers a payoff of $\$ 1$ regardless of the other players' decision. The game is first played with participants randomly matched in pairs, so that there can be no explicit discussion of strategy between players. Shown as a two player, 2 X 2 payoff matrix, cooperation at high effort is a Nash equilibrium, though it is neither a dominant strategy equilibrium nor a prisoners' dilemma. Later, when students are put in larger groups with the same rules regarding payoffs, cooperation at high effort becomes less common. This game offers a good lesson in the difficulties of cooperative decision making, but differs from our cartel game because in the Capra and Holt game players are not allowed to openly collude. Also, in the Capra and Holt game there is no incentive to cheat on an agreement. Players can't increase their earnings by claiming to offer high effort, then choosing low effort.

A game that does directly address oligopoly decision making is introduced by Meister (1999). Like our cartel game, in Meister's game students are asked to make an output decision within a small group of players, and the total amount of output produced determines prices and profits. This game is played over multiple class periods, with students submitting an output decision in one class period, the market price announced the next class period, and students having until the following class period to contemplate their next output decision. In Meister's game, collusion is strictly prohibited. In fact, at the start of the game students sign a pledge not to discuss the game with others in the class. His game is meant to illustrate strategic decisions in an oligopoly market over time, with players adjusting their output decisions based on what they think others in their group will do. Meister does suggest the possibility of allowing explicit cooperation as a possible extension of the game, but discussion of this alternative is limited.

Caudill and Mixon (1994) offer another kind of evidence for cartel behavior in a classroom setting. They use a policy of curving exam scores as a way to illustrate the incentives facing cartel members. All exam scores are curved up a number of points equal to the difference between the class average and 72, or zero points if the average is above 72. Thus, students could all collude and take scores of zero, thereby all getting a curved grade of 72 with no effort. However, individual students have an incentive to break the agreement, study, and earn a score above zero. This strategy reduces the curve (analogous to revenue) for everyone else while the individual student earns a better test grade. The authors discuss how various characteristics of a class and of individual students will affect the chances that such a collusive agreement will succeed. While we suggest that most students may never find themselves facing a cartel decision in their working life, Caudill and Mixon demonstrate that students face this very situation in every class.

None of these other games explicitly addresses the benefits and dangers of openly collusive behavior. In our experiment, participants are encouraged to openly collude and can readily see the benefits of behaving as a monopoly in order to maximize profits for the group. However, they also quickly come to understand the tenuous nature of cartel agreements and the incentive for individual members to cheat on the cartel. Our game also has advantages in its simplicity and the ease with which variations in the rules can be made in order to explore various aspects of cartel behavior. Some of these variations will be described later, but first the basic game is described in detail. 


\section{DESCRIPTION OF THE GAME}

This experiment is an adaptation of a game described by Holt and Laury (1997) that uses playing cards to represent contributions toward a public good and to demonstrate the concept of free-riding. The play of the cartel game is the same as the Holt and Laury game, but rather than using cards to represent their contributions toward a public good, students in the cartel game use combinations of red and black cards to reveal their firm's output decision to the instructor. Total output from the group then reveals a price for the good based on a specified inverse demand function, and players compute their earnings based on the price and the quantity that they produced.

We will explain the game for ten firms, but it can be easily adjusted to other numbers of firms ${ }^{1}$. As pregame preparation take from a deck of ordinary playing cards those cards valued ace through ten ${ }^{2}$ and group together the four suits of each value. At the beginning of the game, hand one set of four cards, two red and two black, to each firm $^{3}$ or player. In the front of the room post the market demand schedule for units of output produced by all firms together. You may keep the demand schedule hidden and simply announce a market price based on total output, but it is fine, and in some ways more helpful, for the players to see the price and quantity combinations for market demand. An example of a demand schedule for a ten-player game is shown in Table 1. You may alter the demand schedule as you like, but a simple demand formula of $\mathrm{P}=2 \mathrm{~N}-\mathrm{Q}$, where $\mathrm{N}$ is the number of firms and $\mathrm{Q}$ is the total output produced, works well and can be easily adjusted for more or fewer firms. At maximum output, a price of $\$ 0.75$ is listed rather than zero ${ }^{4}$.

All firms hold four playing cards: two red and two black. Each firm will make a production decision by handing in two cards face down to the instructor. The number of units produced is equal to the number of red cards that are turned in. If a firm wants to produce two units, then he hands in two red cards. If the player wants to produce just one unit, then he hands in one red card and one black card. Production decisions of zero units are unlikely, but to do so the player hands in two black cards. There will always be two cards handed in, with their colors hidden from the other firms. In this way, no one knows the production decision of any other player.

Once all cards are collected the instructor counts the total number of red cards turned in by all firms and announces the total output level for that round. The instructor also announces the market price based on total output and instructs the players to record their earnings for that round. Cards are returned to the firms. When distributing cards to the firms at the beginning of the game it is helpful for them to have the red and black cards of the same value to identify each firm or player. Identifying each firm in this way will ensure that the correct cards are returned to them after each round. It is also helpful to return the cards in the order in which they were collected in order to ensure that each firm gets the correct cards back ${ }^{5}$. Firms will then make a production decision for the next round. It is important that they understand that their decisions

\footnotetext{
${ }^{1}$ Since there are only 13 card values in a deck, it is best to keep the number of firms at 13 or less. Multiple decks can be used for more players, but that situation could get confusing for the instructor.

${ }^{2}$ Or whatever is the number of players. This description is for a group of 10 players.

${ }^{3}$ If there are too many students in the class, they can be grouped into firms, with each firm consisting of 1-3 players and each firm making a single production decision. Firms are identified by the face value of the set of cards each receives. With three students per firm the game is easily played in classes of up to 39 students (13 firms maximum - see footnote 1). Adding more than three students per firm allows for playing the game in even larger classes, but running the game in a timely, organized manner becomes more difficult.

${ }^{4}$ Even though marginal cost is zero, so that a perfectly competitive price should be zero and profit also zero, we want to make sure that students always have the opportunity to earn some money, even when everybody offers 2 units of output. Also, a price greater than zero is necessary to illustrate the dominant strategy of the cheater - 2 units will always provide more revenue for the individual firm.

${ }^{5}$ Cards do not have to be returned in the order in which they were collected, but it is easier to make sure that the cards are returned to the correct firm if done in this way. It is important that all players have two red and two black cards, and if the wrong cards are returned to a firm the firm may not get the right combination of colors. Also, if the wrong cards are returned to a firm they will be made aware of another firm's production decision. An alternative to returning the cards in the same order in which they were collected would be to call out the numbers on the face of the cards and have the firms retrieve them.
} 
each round are independent. Their production in any given round does not affect their production in subsequent rounds.

In the first few rounds, firms must make their production decisions privately, without talking to any other players. In later rounds, they are allowed to talk to each other and discuss a production strategy; however, their own production decision is still made independently and anonymously. The total number of rounds is flexible. Three or four rounds of private decisions made first, followed by three or four rounds of decisions with collusion works well without taking up too much class time. We allow students up to three minutes to make a production decision ${ }^{6}$. With about two minutes necessary to collect the cards, count them, announce a price, and return the cards, six to eight total game rounds can be completed in thirty to forty minutes, well within the limits of a one hour class period. After all rounds are completed, students tabulate their total earnings for the game, and you can begin discussion of the outcomes of each round.

Table 1

Market Demand Schedule for a Ten-Player Game

\begin{tabular}{cc}
\hline \hline Total Units Produced & Market Price Per Unit \\
\hline 1 & $\$ 19$ \\
2 & 18 \\
3 & 17 \\
4 & 16 \\
5 & 15 \\
6 & 14 \\
7 & 13 \\
8 & 12 \\
9 & 11 \\
10 & 10 \\
11 & 9 \\
12 & 8 \\
13 & 7 \\
14 & 6 \\
15 & 5 \\
16 & 4 \\
17 & 3 \\
18 & 2 \\
19 & 1 \\
20 & 0.75 \\
\hline
\end{tabular}

Note: This market inverse demand function is $\mathrm{P}=2 \mathrm{~N}-\mathrm{Q}$, where $\mathrm{N}$ is the number of firms. A price of $\$ 0.75$ is used for 20 units rather than a price of $\$ 0$.

\section{EXPECTED OUTCOMES}

Students in the first round or two usually attempt to earn maximum revenue for themselves by producing the most units of output they can, so it is common to end up with 16 or 17 total units of output in these rounds. However, players quickly realize that this much output greatly reduces the market price. Many students then decide that if they produce only one unit they might earn more revenue, as long as everyone else does the same. But since they are not allowed to talk to each other about production decisions, their own decision becomes a gamble: will everyone come to the same realization and limit their output, or will they simply give up revenue by offering only a single unit for sale?

\footnotetext{
${ }^{6}$ When making decisions on their own students can typically make a decision very quickly, and even when allowed to collude it doesn't take the class long to decide on a strategy.
} 
After the initial rounds of non-collusive decisions, further instructions are read to introduce the collusive rounds of the game (see appendix). Players should still only have about three minutes to make a decision, although the instructor may want to allow a couple of extra minutes during the first collusive round so that students have more time to get used to the new format and discuss a strategy for the whole group. When the players are allowed to talk to each other about their production decision, several will have already realized that the group earns maximum revenue if they all keep their production at one unit each. At this point, they are acting as a cartel. They are colluding to limit output in order to provide maximum total profit for the group. In the first round of this collusive behavior, they may actually produce the revenue maximizing output. However, soon some players realize that if they "cheat" on the groups' agreement by offering two units of output they can gain a great deal more revenue. In later rounds, even after players are allowed to collude, total output tends to rise back up to the pre-collusion levels of output because of the actions of one or more "cheaters".

A sample of actual game results are presented in Table 2. Some observations can be with regard to these typical results in this setting. One observation is that in the sessions we have conducted there has never been a round with perfect collusion yielding the highest revenue (profit) for the group as a whole and also there has never been a round in which every firm produced two units. A second observation is that firms that choose an output of one in the first round may increase their output in the second then revert to one again suggesting a trigger strategy. A third observation is that it is common for some firms to "cheat" or produce 2 units in every round. When they do they have always been the most profitable firm for the entire session. Note, however, that during the colluding rounds, had everyone stuck to the cartel strategy and produced only one unit of output, everyone would have earned $\$ 40$ over those four rounds. No one, not even those who cheated each round, earned this much in the last four rounds.

Table 2

Sample Game Outcome

\begin{tabular}{|c|c|c|c|c|c|c|c|c|c|}
\hline \multicolumn{10}{|c|}{ Output Choice } \\
\hline & \multicolumn{4}{|c|}{ No Collusion Rounds } & \multicolumn{4}{|c|}{ Collusion Rounds } & \multirow{2}{*}{$\begin{array}{r}\text { Total } \\
\text { Profits }\end{array}$} \\
\hline Firm\# & 1 & 2 & 3 & 4 & 5 & 6 & 7 & 8 & \\
\hline 1 & 1 & 2 & 2 & 2 & 2 & 1 & 1 & 2 & $\$ 39.00$ \\
\hline 2 & 1 & 2 & 1 & 2 & 2 & 1 & 1 & 1 & $\$ 32.00$ \\
\hline 3 & 1 & 2 & 2 & 2 & 2 & 1 & 2 & 2 & $\$ 44.00$ \\
\hline 4 & 2 & 2 & 2 & 1 & 1 & 1 & 1 & 1 & $\$ 37.00$ \\
\hline 5 & 1 & 2 & 2 & 2 & 2 & 2 & 2 & 2 & $\$ 49.00$ \\
\hline 6 & 2 & 2 & 1 & 1 & 2 & 2 & 2 & 2 & $\$ 48.00$ \\
\hline 7 & 2 & 2 & 2 & 2 & 2 & 2 & 2 & 2 & $\$ 54.00$ \\
\hline 8 & 1 & 1 & 1 & 2 & 2 & 1 & 1 & 2 & $\$ 34.00$ \\
\hline 9 & 2 & 2 & 1 & 2 & 1 & 2 & 2 & 2 & $\$ 48.00$ \\
\hline 10 & 2 & 2 & 2 & 2 & 2 & 2 & 1 & 1 & $\$ 46.00$ \\
\hline $\mathbf{Q}$ & 15 & 19 & 16 & 18 & 18 & 15 & 15 & 17 & \\
\hline $\mathbf{P}$ & $\$ 5$ & $\$ 1$ & $\$ 4$ & $\$ 2$ & $\$ 2$ & $\$ 5$ & $\$ 5$ & $\$ 3$ & \\
\hline
\end{tabular}

During the following discussion, cartel breakers often deny that they are "cheating" stating that they did not actually agree to collude. Notice that in the first round in which the firms may collude the output often does not fall much. Most participants by this time are suspicious of others commitment. At this point, it is not uncommon for participants to become quite vocal and upset about why they classmates are not willing to allow them to earn the most points (profits) possible. Output then usually decreases (increasing the price) somewhat but rarely is the output much more than it was in the very first round. In a ten firm game, the highest price we have observed is $\$ 9$ and that was because one firm produced zero units. Sometimes a firm early in the experiment will choose an output of zero apparently thinking that in later rounds others might return the favor and allow them to earn higher profits. A final note is that during the course of the game, the participants that are the most vocal about the fact that each firm should produce only one unit each are often the ones most likely to "cheat". 


\section{CLASSROOM DISCUSSION}

Discussion of the outcomes in each round of this game can take several paths. The obvious approach is to discuss the definition of a cartel and the output decision within a cartel. If the players collude and act as a single monopolist maximum profits will be earned for the group if everyone restricts output to a single unit. The group revenues for all levels of output are shown in Table 3. This table can be shown to students after the game is played to help the discussion. In this game, maximum possible revenue for the group is $\$ 100$, equal to $\$ 10$ per cartel member.

Next the discussion can turn to the reason that cartels may not last very long, that is, that there is an incentive for an individual member to cheat on the cartel and produce extra output. If nine people in the group each contribute a single unit of output and one "cheater" contributes two units, the cheater will earn an extra $\$ 8$ (two units at $\$ 9$ each equals $\$ 18$, versus $\$ 10$ in earnings for the cartel strategy). Given that each player's production decision is secret, there is incentive for a player to cheat on the cartel agreement and produce extra output. Unfortunately, all firms face this same incentive and if several decide to cheat on the cartel agreement in the same round, the price of their output will fall and they may end up earning less than the $\$ 10$ revenue they would have earned if everyone had followed the cartel strategy. In this game, if there are five or more cheaters, the cheaters' revenue will fall below the cartel strategy level of $\$ 10$, while greatly reducing the revenue of those firms who stuck with the cartel strategy and sold only a single unit of output ${ }^{7}$.

Table 3

Total Revenue Earned by All Players

\begin{tabular}{|c|c|c|}
\hline Total Units Produced & Price Per Unit & Total Revenue \\
\hline 1 & $\$ 19$ & $\$ 19$ \\
\hline 2 & 18 & 36 \\
\hline 3 & 17 & 51 \\
\hline 4 & 16 & 64 \\
\hline 5 & 15 & 75 \\
\hline 6 & 14 & 84 \\
\hline 7 & 13 & 91 \\
\hline 8 & 12 & 96 \\
\hline 9 & 11 & 99 \\
\hline 10 & 10 & 100 \\
\hline 11 & 9 & 99 \\
\hline 12 & 8 & 96 \\
\hline 13 & 7 & 91 \\
\hline 14 & 6 & 84 \\
\hline 15 & 5 & 75 \\
\hline 16 & 4 & 64 \\
\hline 17 & 3 & 51 \\
\hline 18 & 2 & 36 \\
\hline 19 & 1 & 19 \\
\hline 20 & 0.75 & 10 \\
\hline
\end{tabular}

The decision of the cheater hinges on comparing marginal revenue and marginal cost. Marginal revenue for the cheater is greater than marginal cost (in this case marginal cost is zero), so that profit maximization for the single firm, as opposed to the cartel, requires producing two units of output rather than one unit. Of course, this marginal

\footnotetext{
${ }^{7}$ Note that in discussion of actual results in Table 2, players who cheated during the collusive rounds did not earn as much as they would have had everyone cooperated.
} 
revenue over marginal cost outcome for a cheater depends on all, or at least most, of the other firms' following the cartel strategy.

Further discussion may involve actual cartels and their behavior, whether cheating has occurred, and what steps the cartel can take to ensure that cheating does not occur. The experiment described in this paper is a repeated game in which firms never know each other's production levels or which participant is a cheater ${ }^{8}$. Discussion can be directed towards questions such as how behavior might be different if everyone's production decision were revealed to the other players. This scenario may be more realistic since it is likely that in a real cartel situation members will know who has broken the output agreement. The instructor may also invite discussion about how cartels might discourage cheating, such as through the cultural ties of OPEC countries ${ }^{9}$ or the possible threat of violence within drug cartels. It is simple to alter the rules of this game to investigate some of these issues, a topic that we will address later in the paper.

A more advanced presentation and discussion involves a game-theoretic approach. The decision of a cartel member is presented in Figure 1 as a two-player payoff table. One player represents a person considering cheating on the cartel (the "Cheater"), and the other player represents the nine other members of the cartel who cooperate with the cartel decision (the "Cooperators") ${ }^{10}$.

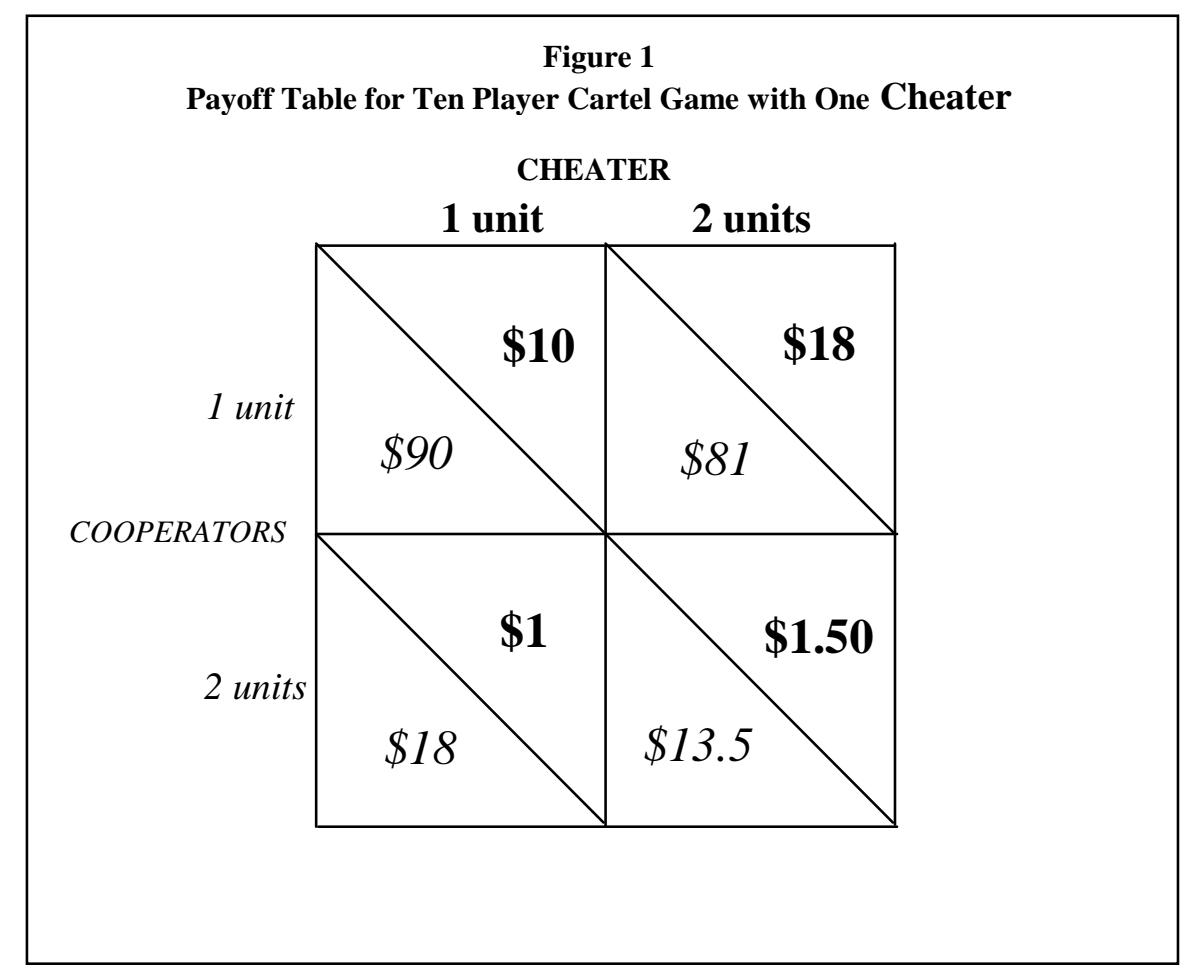

\footnotetext{
${ }^{8}$ During the game there is often much outspoken speculation on who is cheating. This discussion can be lively and entertaining and ensures that students will not soon forget the play of the game, nor each other! Small classes that have been together for a long time can be especially quick to judge who is cheating on the group.

${ }^{9}$ For example, you can discuss the implications of Venezuela being the only non-Middle Eastern OPEC cartel member during the 1970's.

${ }^{10} \mathrm{We}$ assume for the purposes of this payoff table that all other cartel members (Cooperators) take the same action.
} 
Using the payoff table, it is evident that the dominant strategy for the cheater is to produce two units of output, because this player always does better producing two units than one unit. The dominant strategy of the nine cooperating others is to produce one unit each. Again, this strategy always results in a better payoff than two units regardless of the decision of the cheater. The outcome of one unit from the cheater and two units from the rest of the cartel is a dominant-strategy equilibrium. It is the outcome that should be expected in this simple game and is further evidence for expecting at least one member to cheat on a cartel agreement.

While other cooperative games described in this paper, such as Seiver (1995), present situations equivalent to the prisoners' dilemma, the payoffs in our cartel simulation do not represent the classic prisoners' dilemma. A prisoners' dilemma arises when the dominant strategy outcome results in all firms being worse off than if they had cooperated. This situation is not the case in our payoff matrix. The cheater is clearly better off by not cooperating. However, since all firms see the same payoff table from the perspective of a potential cheater, a problem arises that more than one firm may cheat, possibly reducing revenue even for the cheaters.

If this game were played with only two firms, then the payoff table would represent a classic prisoners' dilemma. Figure 2 represents the payoffs in a two firm game in which the dominant strategy is for both firms to produce two units of output, even though both would be better off by cooperating and producing only 1 unit each. However, once the game consists of more than two firms and there is the possibility of collusion by multiple firms, the prisoners' dilemma no longer holds. The change in the dominant strategy for the cartel members that stick to the agreement does rely on the assumption that most members will stick to the production agreement, and this outcome is common. Any time we have run this game it has never been the case that all firms cheated on the agreement, and in many cases a majority of the firms stick to the cartel strategy, with only a few cheaters.

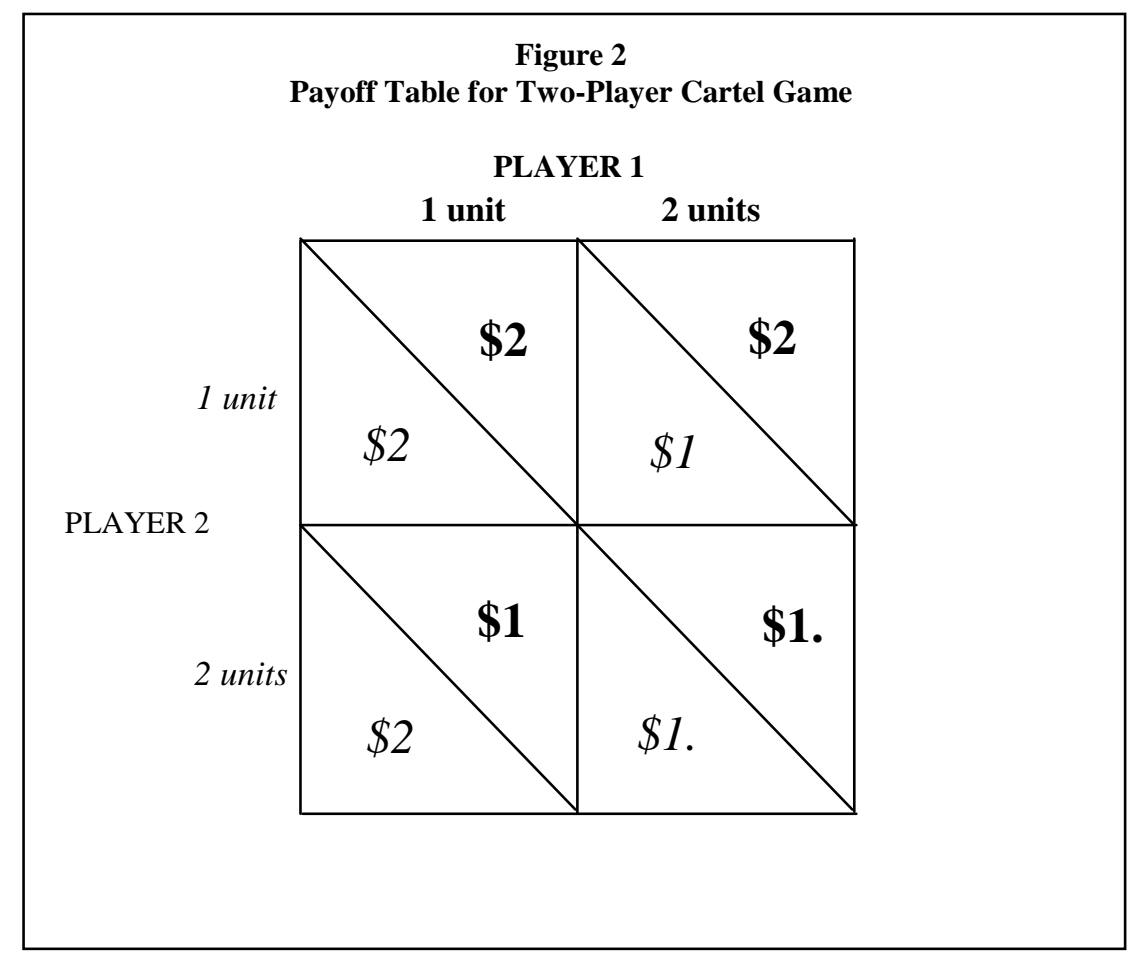

The result that some, if not most, firms always stick to the agreement can be explained to students based on the figure 1 payoff table showing that it is the dominant strategy for the rest of the cartel to hold together and let one member cheat. Those students who stick to the agreement often offer their own explanation of the result. When 
asked why they continued producing only one unit of output even though they know that some firms will cheat, many students have explained that if everyone cheated then everyone's profits would be a lot smaller, whereas even if a few firms benefit by cheating, a cooperating firm will still earn more money by restricting its own output. This explanation is another way to describe the situation in figure 1 in which it is a dominant strategy for cooperating firms to stick to one unit of output, even though a cheater will make more money. When everyone cheats, everyone earns much less ${ }^{11}$.

To further stimulate thoughts and discussion, students can be required to answer a set of questions about the cartel game or to write a paper about their experience with the game. They can address simple questions such as "what is a cartel?" or "what is the basic strategy followed by a cartel?" Questions might include whether their production strategy was different in the rounds in which their own decision compared to rounds in which they were allowed to openly collude, whether or not they were a "cheater" during the cartel rounds, why or why not, and whether they would have made more money had they pursued a different strategy. You can also ask them to compare everyone's actual earnings to a scenario in which all firms followed the cartel strategy. Usually very few people, if any, end up earning as much money as they would have had everyone followed the cartel strategy throughout.

\section{EXTENSIONS OF THE GAME}

One of the strengths of this cartel game is the ease with which it can be modified and expanded. The instructor can easily change or add rules in order to examine various aspects of cartel behavior. For example Levenstein and Suslow (2006) suggest monitoring as a viable way to maintain cooperative behavior. If firm's output decisions are revealed to the class each round, firms may be less likely to cheat. We have often observed that the most vocal proponent of cooperating during the collusive rounds is a firm that is actually cheats. Revealing output decisions may alter that behavior. A variety of rules for revealing the output could be tested such as revealing the output of a single firm chosen at random or revealing all firms' output in a round.

Other possible modifications can be made. For example, there may be some type of punishment for cheaters when caught, such as surrendering revenue to the rest of the firms. We have observed students voluntarily revealing their decision to cheat in part because they perceive no consequences from the group for their cheating. Levenstein and Suslow (2006) propose that the number of firms in an industry can be a factor in the success of a cartel. Therefore, reducing the number of firms by splitting the class into smaller groups may be an interesting variation. Finally, one can suggest specific strategies to the group or to individual firms to test possible outcomes. One such strategy might be the "grim strategy" of a firm offering to cooperate until another firm cheats and then increasing its own output. The possible variations on the game are limited only by the imagination of the instructor.

\section{CONCLUSIONS}

While most students will not likely find themselves acting in a cartel, they may during their business careers face non-cooperative situations where it may be advantageous to cooperate. This game offers students a way to understand the incentives faced by members of an explicit cartel and the difficulties inherent in holding a cartel together. By extension the students can learn that in any business decision in which cooperation can yield benefits there are inherent difficulties in even tacit coordination. There can be dangers involved in cooperative behavior that do not simply involve the law, but that involve fundamental incentives to members of any cooperative effort. This classroom experiment in cartel behavior can help economics students understand the incentives and decisions facing cartel members. In-class demonstrations such as this cartel game offer an enjoyable and memorable opportunity for economics students at all levels to experience economic principles at work.

\footnotetext{
${ }^{11}$ It is important that in this game the students are playing for money, either paid as cash or, more likely in a classroom setting, to exchange for bonus points at a rate determined by the instructor. Playing for money ensures the proper incentives to engage in economic behavior. Playing for bonus points eliminates the possibility of revenue transfers among students and agreements to divide earnings equally after class. If the game is played for cash, discussion of revenue transfers should be explicitly forbidden.
} 


\section{APPENDIX}

Instructions for the game

The following instructions are read aloud:

Instructions: You are all producers of a good, X. You all produce the same good, and your products are indistinguishable. All of your goods are sold in a common market characterized by the demand schedule as shown (have the demand schedule posted in front of the room). During this game you will make a series of production decisions divided into game rounds. During each round you choose a level of output to contribute to the market. You may choose to produce as many as two units of output per round. Your output decisions in any single round do not affect your output in subsequent rounds. You make your output decision by handing two of your playing cards, face down, to the instructor. The number of units of output you have chosen will be indicated by the number of red cards that you turn in: two red cards indicates production of two units of output, one red card and one black card indicates production of one unit of output, and two black cards would indicate production of zero units of output. You must always turn in two cards so that your production decision is unknown to the other players. Once all of the players have turned in their cards, the instructor will count the total number of red cards turned in, representing the total amount of output produced by the group. The result will then be announced to the players. The instructor will also announce the market price based on the demand schedule. You will record your revenue for the round based on the number of units of output you produced and the price per unit of that output. Production costs are zero so that your total earnings are represented by revenue. Your cards will be returned to you and you will then repeat the decision in a new round. Once again, production decisions in each round are independent. For the first few rounds, you will make your production decision on your own, without talking to the other players. In later rounds you will be allowed to discuss your output decision with one another before turning in your cards, however, your own production decision will still be unknown to everyone else.

At the start of the collusive rounds, further instructions may be read:

Further instructions: During the remaining rounds of the game you are allowed to collude with other firms regarding the number of units of output that you will produce. Take the next three or four minutes to discuss a strategy, then submit your output decision to the instructor in the same manner as before. Again, cards are turned in face down so that your own output decision is unknown to the other firms.

\section{REFERENCES}

1. Capra, C. M. and C.A. Holt. 1999. Coordination. Southern Economic Journal 65(January): 630-36.

2. Caudill, S.B. and F.G. Mixon, Jr. 1994. Cartels and the incentive to cheat: evidence from the classroom. Journal of Economic Education 25(Summer): 267-69.

3. DeYoung, R. 1993. Market experiments: the laboratory versus the classroom. Journal of Economic Education 24(Fall): 335-351.

4. Holt, C.A. and S.K. Laury. 1997. Classroom games: voluntary provision of a public good. Journal of Economic Perspectives 11(Fall): 209-15.

5. Levenstein, M. C. and V. Y. Suslow. 2006. What determines cartel success? Journal of Economic Literature 44 (March): 43-95.

6. Meister, J. P. 1999. Oligopoly - an in-class economic game. Journal of Economic Education 30(Fall): 383391.

7. Seiver, D. 1995. A simple game theory experiment for teaching oligopoly. Classroom Expernomics 4(Fall): 1-2.

8. $\quad$ Stigler, George. 1964. A theory of oligopoly. Journal of Political Economy 72(1): 44-61.

9. Yakhou, M. and V.P. Dorweiler. 2007. Fostering cross-functional skills and attitudes in business Administration students. College Teaching Methods and Styles Journal. 3(2): 49-57. 